American Journal of Pharmacology and Toxicology 2 (4):170-177, 2007

ISSN 1557-4962

(C) 2007 Science Publications

\title{
A Combined Phytohemagglutinin and $\alpha$-Ketoglutarate Pharmacology Study of Gut Morphology and Growth in Older Adult Rats
}

\author{
${ }^{1,2}$ R. Filip, ${ }^{3}$ A. Harrison and ${ }^{1}$ S.G. Pierzynowski \\ ${ }^{1}$ Department of Cell and Organism Biology, \\ Lund University, Helgonavagen 3b, 22362 Lund, Sweden \\ ${ }^{2}$ Institute of Agricultural Medicine, Jaczewskiego 2, 20-950 Lublin, Poland, \\ ${ }^{3}$ Department of Animal and Veterinary Basic Sciences, Faculty of Life Science, \\ Copenhagen University, Gronnegaardsvej 7, 1870 Frederiksberg C, Denmark
}

\begin{abstract}
This study has evaluated the effect of phytohaemagglutinin (PHA) in combination with alpha-ketoglutaric acid (AKG), on GI-tract morphology and $\mathrm{N}$ balance in adult rats. Rats, aged approx. 15 months, were assigned to one of four experimental groups, (1) Control group, (2) AKG group, (3) AKG+PHA 100\% group and (4) AKG+PHA $1 \%$ group. AKG and AKG+PHA were administered via a stomach tube. Rats were treated for a period of 7 days before being killed humanely. Lighter GI-tract weights were found in the AKG and AKG+PHA $1 \%$ groups $(6.8 \%, p<0.05$ and $p<0.01$, respectively) compared to that of Control rats, whilst AKG+PHA $100 \%$ treatment resulted in no such loss of GItract total weight. Interestingly, AKG, AKG+PHA $1 \%$ and AKG+PHA $100 \%$ treatment resulted in a significant $114 \%(p<0.05), 116 \%(p<0.001)$ and a $145 \%(p<0.001)$, increase in duodenal crypt depth, respectively. Moreover, AKG, AKG+PHA $1 \%$ and AKG+PHA $100 \%$ treatment induced a $107 \%$ $(p<0.05), 109 \%(p<0.001)$ and a $119 \%(p<0.001)$, increase in the thickness of the tunica mucosa of the proximal GI-tract, respectively. However, whilst there was a trend towards a reduction in $\mathrm{N}$ excretion in urine for the AKG+PHA $100 \%$ group, compared to that of the Controls (14.3\% lower), this difference was not found to be statistically significant. In conclusion, a combination of PHA and AKG treatment (AKG+PHA 100\%) stimulates proliferation of GI-tract crypt depth and tunica mucosa thickness cf. that of Control rats, findings that would be of benefit to the elderly and to individuals suffering from drug induced GI-tract erosion and injury.
\end{abstract}

Key words: AKG, PHA, GI-tract, ageing

\section{INTRODUCTION}

Many of the most prominent age-related changes of the gastrointestinal tract (GI-tract) are due to a senescent decline in absorptive processes, or the consequence of a compromise in nutritional status ${ }^{[1,2]}$. Indeed, following a period of stress, be this either illness or injury related, elderly patients often exacerbate things by continuing to underfeed themselves for 10-15 days, while younger patients increase their energy intake ${ }^{[2]}$. One might therefore conclude that elderly patients have, put quite simply, a reduced functional reserve of their intestine.

The interaction of red kidney bean (Phaseolus vulgaris) lectin, phytohaemagglutinin (PHA), with the GI-tract is well documented ${ }^{[3,4]}$, indeed it has been shown that PHA accelerates the turnover of GI-tract cells. Such rapid cell proliferation might be expected to result in both increased gut growth and functional maturation and as a further consequence, an increase in the use of dietary amino acids for protein synthesis by enterocytes ${ }^{[4,5]}$. Animal studies have shown that over a 3 day period oral administration of PHA to young suckling rats results in gut maturation in terms of epithelial development, decreased lactase but increased maltase and sucrase activities as well as a reduction in macromolecular absorptive capacity, sometimes referred to as gut closure ${ }^{[6]}$. Moreover, PHA can affect the pancreas, inducing an increase in its weight relative to that of the whole body (BW) as well as enhancing its exocrine function ${ }^{6}$.

Alpha-ketoglutaric acid (AKG), a glutamine derivative, is considered to be one of the crucial molecules in trans-membrane amino acid transport, protein metabolism and both gene and cellular redox regulation ${ }^{[7]}$. Both animal and human studies have

Corresponding Author: S.G. Pierzynowski, Department of Cell and Organism Biology, Lund University, Helgonavagen 3b, 22362 Lund, Sweden Tel: +46 709780202 Fax: +46462224381, +4646 2224539 
shown that $95 \%$ of luminal glutamate and $70 \%$ of glutamine, yet only $40 \%$ of AKG, is metabolized (first pass) to $\mathrm{CO}_{2}$ by the intestinal mucosa ${ }^{[8-11]}$. Deamination of amino acids releasing amino nitrogen for growth, results in the production of ammonia, which is generally protonated to ammonium at physiological $\mathrm{pH}$. Ammonia is toxic for the body, therefore it is maintained at a very low level in the blood. In pigs post-weaning, extracellular or intra-mitochondrially generated ammonia may by converted to urea by enterocytes ${ }^{[12]}$. On the other hand, ammonia may itself be an essential part of the environment needed for growth of enterocytes ${ }^{[13]}$. In support of which, AKG has been shown to exert a beneficial effect on nitrogen metabolism through facilitating ammonium conversion to amino acids and protein and by reducing levels of ammonium in the body ${ }^{[14]}$. Moreover, AKG has the potential to restore acid base homeostasis, spare nitrogen, decrease bone turnover and improve renal function in the catabolic acidotic patient, proving to be successful in patients with Chronic Renal Failure $(\mathrm{CRF})^{[15,16]}$.

Hypothetically, an increased cellular turnover in enterocytes upon addition of PHA, resulting in an increase in ammonia production, will in the presence of AKG, rather promote its incorporation into amino acids and reduce the level of urea production. Previously, we have shown that combined administration of PHA and AKG in growing rats stimulates small bowel growth by increasing crypt depth and the weight of the small intestine, resulting in, a higher rate of protein production in the intestinal wall and an apparent change in the proportion of $\mathrm{N}$ excretion via urine and faeces, in favour of faecal excretion ${ }^{[17]}$. However, the potential for treatment of injured intestinal mucosa through PHA and AKG administration in the ageing gut remains untested.

The aim of the present study was therefore to investigate the effect of oral supplementation of two different doses of PHA in combination with $\mathrm{AKG}$ on GI-tract morphology and growth, as well as nitrogen balance in older rats. It is hypothesized that an increase in enterocyte turnover and an increased protein turnover of the intestine after oral PHA and AKG administration is achievable in older animals.

\section{MATERIALS AND METHODS}

Rats came from the Sprague Dawley outbred Laboratory (M and B A/S, Denmark) and were caged individually in metabolic cages $(60 \%$ humidity with $12 \mathrm{~h}$ of light $24 \mathrm{~h}^{-1}$ ) at the Deptartment of Animal Physiology, Lund, Sweden. Rats were given ad libitum access to food, a wheat, barley, extracted soya bean meal, fat blend, mineral, vitamin and amino acid mix with a dietary composition (\%) Dig. Crude Protein 17.37, Dig. Crude Oil 3.76, Calcium 0.65, total Phosphorus 0.51 of which 0.24 was available, Lysine 1.26 and Methionine 0.30 and a Dig. Energy of $13.75 \mathrm{MJ} \mathrm{kg}^{-1}$. The vitamin content $\mathrm{kg}^{-1}$ of diet comprised, Vitamin A, 14960 I.U, Vitamin $\mathrm{D}_{3}$, 1574 I.U, Vitamin E, $110.4 \mathrm{mg}$, Thiamin, $17.6 \mathrm{mg}$, Riboflavin, $13.2 \mathrm{mg}$, Pyrodoxine, $17.9 \mathrm{mg}$, Vitamin B12, $35 \mu \mathrm{g}$, Vitamin K, $19.9 \mathrm{mg}$, Folic Acid, $3.1 \mathrm{mg}$, Nicotinic Acid, $34.1 \mathrm{mg}$, Panthotenic Acid, $34.1 \mathrm{mg}$, Choline, $1557.0 \mathrm{mg}$, Inositol, $1811.4 \mathrm{mg}$, Biotin, $369.2 \mu \mathrm{g}$. The study was approved by the Ethical Review Committee for Animal Experiments at Lund University and was conducted according to European Community regulations concerning the protection of experimental animals.

Groups were equalised with regard to body weight. Food and water consumption as well as urine and faeces production were measured daily. Treatments and experimental conditions were conducted according to the recommendations of the Federation of the European Laboratory Animal Science Association (FELASA).

Experiment design: Twenty three rats (12 males/11 females) aged 50-60 weeks and with an initial body weight of $428 \pm 90 \mathrm{~g}$, after a 3 week adaptation period, were randomly assigned to four experimental groups: 1) Control, 2) AKG, 3) AKG + PHA 100\% and 4) AKG+PHA $1 \%$ with 5 animals in the Control group and 6 in the treatment groups. The stock solution of crude PHA in $0.9 \% \mathrm{NaCl}$ was $(20 \% \mathrm{w} / \mathrm{v})$ in water: $50 \mathrm{mg}$ PHA $\mathrm{mL}^{-1}$. Control rats were administered water enriched with electrolytes and 0.1M HCL, pH 4.6. Group 2 rats were given water enriched with electrolytes and $0.1 \mathrm{M}$ AKG. Group 3 rats were administered water enriched with electrolytes and $0.1 \mathrm{M} \mathrm{AKG}+\mathrm{PHA}$ (Crude) (PHA-1000 mg kg b. wt., in $0.9 \% \mathrm{NaCl}-20 \mathrm{~mL} \mathrm{~kg}{ }^{-1}$ b. wt.). Finally, group 4 rats were administered water enriched with electrolytes and $0.1 \mathrm{M} \mathrm{AKG}+\mathrm{PHA}$ (Crude) (PHA-10 mg kg-1 b. wt., in $0.9 \% \mathrm{NaCl}-20 \mathrm{~mL} \mathrm{~kg}^{-1}$ b. wt.). Solutions were given every other day via stomach tube ( $20 \mathrm{~mL} \mathrm{~kg}^{-1}$ body wt.) for a period of 7 days.

Urine and faeces sampling: Urine collection via a cup was performed daily. Addition of $10 \mathrm{~mL}$ of a $50 \% \mathrm{H}_{2}$ $\mathrm{SO}_{4}$ solution was used to stop microbial activity. The total volume of urine was measured and a homogenised sample of $10 \mathrm{~mL}$ was collected for urea analysis. Faeces, also collected via a cup, were kept dry. The weight of the faeces was measured daily, after which 
$60 \mathrm{~mL}$ of a $50 \% \mathrm{H}_{2} \mathrm{SO}_{4}$ solution was added. Samples were stored until the end of the experiment, at which time they were analysed for nitrogen content.

Analysis of total nitrogen: Nitrogen content was measured using a Leco Nitrogen and Protein Determinator FP-428 (Leco Corporation. St. Joseph. MI., U.S.A). The instrument was set up in "low range" mode. Prior to analysis, the faecal samples were homogenised (Sorvall Omni-Mixer). The faecal samples, 150-200 mg, were analysed in tin foil cups. The urine samples $(100-200 \mu \mathrm{L})$ were analysed in tin capsules measuring $15 \times 6 \mathrm{~mm}$ (length/diameter). To obtain urine samples for nitrogen determination, aliquots of $1 \%$ of the daily urine volume were pooled. A glycine standard solution containing 1\% nitrogen was used as an internal reference. Nitrogen determinations were made in duplicate.

Collection of GI-tract content and samples for histopathological analysis: At the end of the trial (at an age of 54-64 weeks), stomach contents, proximal and distal small intestine, caecum and colon were collected, weighed and prepared for measurement of AKG concentration. Duodenum was fixed in Bouin's solution and then dehydrated and embedded in paraffin. Paraffin sections $(5 \mathrm{~mm})$ were cut and mounted on Super Frost/Plus slides (Histolab, Sweden). For histological study at the light microscope level, a $\mathrm{H}$ and $\mathrm{E}$ stain was used. Duodenal preparations were measured for crypt depth, tunica mucosa thickness, epithelial cell height and basal width. Forty well-oriented villi and crypts taken from an area devoid of Peyer's patches, were measured at low magnification (objective $\times 2.5$ ) from each animal. Tunica mucosa thickness was measured as the distance from the muscularis mucosa to the tip of the villus, whereas crypt depth was measured from the muscularis mucosa to the level of the crypt opening (Fig. 1). The height of 10 well-oriented villi was measured at high magnification (objective $\times 100$ ). A total of one thousand cells were examined from each animal.

Immunohistochemistry: An immunohistochemical reaction was performed using monoclonal antiserum raised against glutamate at a dilution of 1/1000. An indirect Polystain (Zymed) peroxidase method was applied. Peroxidase was visualised by incubating the sections in a $0.05 \% \quad(\mathrm{v} / \mathrm{v})$ 3.3-diaminobenzidine tetrahydrochloride solution containing $0.01 \% \quad(\mathrm{v} / \mathrm{v})$ hydrogen peroxide. After being rinsed in water, the sections were lightly counterstained with hematoxylin. The specificity of the stain was controlled by substituting the primary antibodies with buffer.

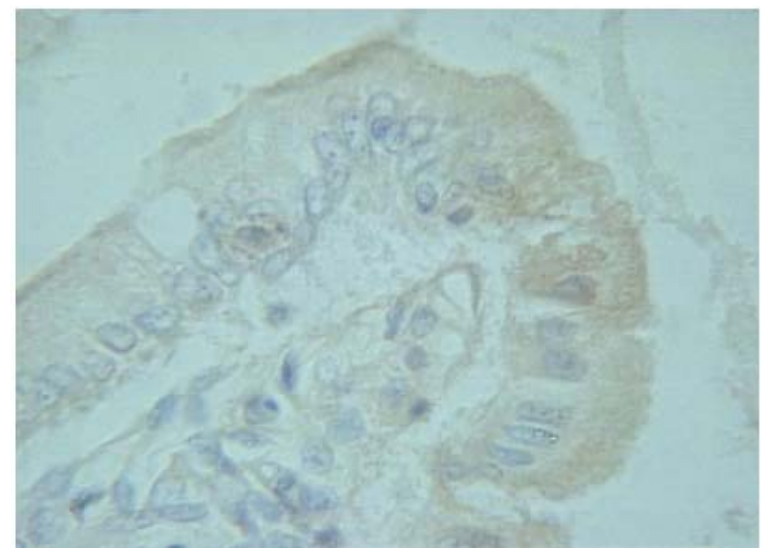

Fig. 1: IHC proved glutamate negative staining of the enterocytes of the proximal part of the small intestine from HCL treated rats

Calculations and statistics: Total feed intake was calculated from the level of food provided $\mathrm{day}^{-1}$, although an approximation was made to compensate for any feed, which entered the cup used for faeces collection. This correction factor was found to be constant for all treatments and amounted to $10.77 \%$ of the total feed provided. The final feed intake was, therefore, adjusted using this factor. The nitrogen level of the feed was calculated from the level of protein in the feed, which was $19.76 \%$. Data, which were normally distributed and of equal variance, were analysed for statistical significance between means using the student's t-test. A comparison of each variable in the histo-pathological analysis was performed using a one-way ANOVA. If the overall ANOVA proved to be significant, pair wise comparisons using a t-test were then performed. In all statistical analyses $\mathrm{p}<0.05$ was considered significant.

\section{RESULTS AND DISCUSSION}

Rat performance: The only significant difference in terms of performance parameters was the lower quantity of faeces produced $(\mathrm{p}<0.007)$ with $\mathrm{AKG}$ supplementation alone (Group 2) cf. the Controls and $\mathrm{AKG}+\mathrm{PHA} 100 \%$ and $\mathrm{AKG}+\mathrm{PHA} 1 \%$ treated rats. Moreover, faecal production in Group 2 was also significantly lower than that of both AKG + PHA groups combined $(p<0.004)$. Also worthy of note was the significant reduction $(\mathrm{p}<0.02)$ in the level of faeces excreted by females ( $22.1 \pm 0.7 \mathrm{~g}$ ) compared to males $(25.3 \pm 0.5 \mathrm{~g})$ within Group 2 itself (data not shown).

A significant difference $(p<0.009)$ in ADFI within the control group, comparing males $(14.7 \pm 0.2 \mathrm{~g})$ with 
females ( $16.8 \mathrm{~g} \pm 0.3 \mathrm{~g}$ ), was found, something that was not noted for any of the other rat groups. Finally, the water intake was significantly reduced in males $(30.3 \pm 8.2 \mathrm{~g})$ cf. females $(62.2 \pm 9.7 \mathrm{~g})(\mathrm{p}<0.05)$ with AKG supplementation alone-Group 2.

A noticeable reduction in the level of urine excreted by both the AKG and AKG+PHA 100\% groups was found compared to that of the controls, however, it was also associated with a concurrent reduction in average daily water intake for these two groups (Table 1).

Gastro-intestinal tract weights: A reduction in total GI-tract weight for the AKG $(\mathrm{p}<0.05)$ and AKG+PHA $1 \%(p<0.01)$ treated rats was found compared to values for the Controls. Results also showed some differences between the sexes in the AKG treatment group e.g., the stomach weighed less in males cf. females $(0.7 \pm 0.2 \mathrm{~g}$ vs $2.2 \pm 0.8 \mathrm{~g}$, respectively), whereas small intestine $(7.6 \pm 0.3 \mathrm{~g}$ vs $9.2 \pm 0.5 \mathrm{~g})$ and total GI-tract $(12.5 \pm 0.4 \mathrm{~g}$ vs $14.9 \pm 0.7 \mathrm{~g}$ ) were found to weigh less in females than in males (all $\mathrm{p}<0.05$ ). Although there were no differences between the Controls and the treatment groups regarding the proportion of GI-tract weight to that of body weight, sex differences were found within the groups (Table 2).
Gastro-intestinal tract morphology: Morphometric analysis of the proximal part of the GI-tract taken from animals treated with AKG, AKG+PHA $1 \%$ and AKG + PHA $100 \%$, revealed a significant difference $(p<0.05)$ compared to that of the Controls with regard to both, 1) crypt depth and 2) tunica mucosa thickness. Interestingly $\mathrm{AKG}+\mathrm{PHA} \quad 100 \%$ treatment increased crypt depth in a more pronounced fashion $(45 \%)$ than the AKG+PHA $1 \%$ treatment. Similarly, the most pronounced change with regard to the thickness of tunica mucosa was found for the AKG+PHA 100\% treated rats (Table 3$)$. In the stomach, a significant increase $(p<0.05)$, in the thickness of the tunica mucosa was found in animals treated with both AKG+PHA 1\% and $\mathrm{AKG}+\mathrm{PHA} 100 \%$ compared to values for the

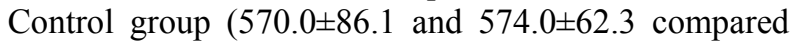
with $519.6 \pm 65.2 \mu \mathrm{m}$ tunica mucosa thickness for the Controls).

A histological examination of the distal part of the GI-tract revealed that there was a diffuse leukocyte infiltration of the tunica mucosa in treated animals. However, there were no pronounced morphological changes in this part of gastrointestinal tract. A diffuse leukocyte infiltration of tunica mucosa in both AKG + PHA $1 \%$ and AKG+PHA $100 \%$ treated animals within the proximal and distal part of the GI-tract was observed (data not presented).

Table 1: Growth performance, urine production and faeces excretion of adult Control rats, or rats treated with AKG, AKG+PHA $100 \%$ or AKG+PHA $1 \%$ for 7 days. Values are means \pm SEM

\begin{tabular}{|c|c|c|c|c|}
\hline Days $0-7^{\mathrm{a}}$ & $\begin{array}{c}\text { Control } \\
(\mathrm{n}=5)\end{array}$ & $\begin{array}{l}\text { AKG } \\
(n=6)\end{array}$ & $\begin{array}{l}\text { AKG+ PHA } 100 \% \\
(n=6)\end{array}$ & $\begin{array}{l}\text { AKG+PHA } 1 \% \\
(n=6)\end{array}$ \\
\hline $\begin{array}{l}\text { Average Daily gain }\left(\mathrm{g} \mathrm{day}^{-1}\right) \\
\text {. }\end{array}$ & $-1.8 \pm 1.1$ & $-3.0 \pm 1.1$ & $-4.8 \pm 1.5$ & $-3.1 \pm 0.9$ \\
\hline Average Daily feed intake $\left(\mathrm{g} \mathrm{day}^{-1 b}\right)$ & $15.5 \pm 0.5^{3}$ & $16.0 \pm 1.4$ & $13.3 \pm 1.6$ & $16.1 \pm 1.1$ \\
\hline Average Daily water intake $\left(\mathrm{mL}\right.$ day $\left.^{-1}\right)$ & $66.4 \pm 14.0$ & $46.3 \pm 8.8^{1}$ & $36.6 \pm 10.7$ & $64.5 \pm 11.5$ \\
\hline Gain:Feed $\left(\mathrm{g} \mathrm{kg}^{-1 \mathrm{c}}\right)$ & $-127 \pm 69$ & $-204 \pm 88$ & $-268 \pm 72$ & $-186 \pm 61$ \\
\hline Urine $\left(\mathrm{mL}\right.$ day $\left.^{-1}\right)$ & $48.4 \pm 10.4$ & $34.1 \pm 6.9$ & $27.0 \pm 7.7$ & $48.5 \pm 9.6$ \\
\hline Faeces $\left(\mathrm{g} \mathrm{day}^{-1 \#}\right)$ & $23.9 \pm 0.8$ & $19.5 \pm 0.9^{* 2}$ & $22.8 \pm 1.1$ & $24.7 \pm 0.9$ \\
\hline
\end{tabular}

HCL (pH 5.1) (HCL) and $\alpha$-ketoglutarate (AKG) (pH 5.1) combined with Phytohemagglutinin (AKG + PHA) at two different levels. ${ }^{a}:$ Average initial and final weights were $427.7 \mathrm{~g}$ and $405.1 \mathrm{~g}$, respectively, ${ }^{\mathrm{b}}:$ Feed intake have been corrected for loss, ${ }^{\mathrm{c}}$ : Treatment AKG+PHA $100(\mathrm{n}=5)$, *: $\mathrm{p}<0.007,{ }^{\#}:$ (AKG vs. AKG + PHA) $\mathrm{p}<0.004,{ }^{1}:$ (m) vs. (f) $\mathrm{p}<0.05,{ }^{2}:$ (m) vs. (f) $\mathrm{p}<0.02,{ }^{3}:$ (m) vs. (f) $\mathrm{p}<0.009$

Table 2: GI-tract weights of adult Control rats, or rats treated with AKG, AKG+PHA $100 \%$ or AKG+PHA $1 \%$ for 7 days. Values are means \pm SEM

\begin{tabular}{|c|c|c|c|c|}
\hline Days $0-7^{\mathrm{a}}$ & $\begin{array}{l}\text { Control } \\
(\mathrm{n}=5)\end{array}$ & $\begin{array}{l}\text { AKG } \\
(n=6)\end{array}$ & $\begin{array}{l}\text { AKG+PHA } 100 \% \\
(\mathrm{n}=6)\end{array}$ & $\begin{array}{l}\text { AKG+PHA } 1 \% \\
(n=6)\end{array}$ \\
\hline Stomach weight (g) & $2.3 \pm 0.1$ & $2.1 \pm 0.1^{1}$ & $2.1 \pm 0.2$ & $2.0 \pm 0.1$ \\
\hline Small Intestine weight (g) & $8.8 \pm 0.6$ & $8.4 \pm 0.4^{1}$ & $9.3 \pm 0.8$ & $8.6 \pm 0.4$ \\
\hline Large Intestine weight (g) & $1.9 \pm 0.3$ & $1.6 \pm 0.1$ & $1.5 \pm 0.1$ & $1.3 \pm 0.1$ \\
\hline Cecum weight $(\mathrm{g})$ & $1.8 \pm 0.1$ & $1.6 \pm 0.0$ & $1.9 \pm 0.2$ & $1.8 \pm 0.1$ \\
\hline Total GI-tract weight $(\mathrm{g})^{\$, t}$ & $14.7 \pm 0.2$ & $13.7 \pm 0.2 *^{2}$ & $14.8 \pm 0.3$ & $13.7 \pm 0.1 * *$ \\
\hline GI-tract weight/bwt (\%) & $3.5 \pm 0.5^{3}$ & $3.5 \pm 0.4^{5}$ & $4.1 \pm 0.3^{4}$ & $3.6 \pm 0.4^{5}$ \\
\hline
\end{tabular}

HCL (pH 5.1) (HCL) and $\alpha$-ketoglutarate (AKG) (pH 5.1) combined with Phytohemagglutinin (AKG+PHA) at two different levels. ${ }^{a}$ : Average initial and final weights were 427.7 and $405.1 \mathrm{~g}$, respectively. ${ }^{*}$ : $\mathrm{p}<0.05, * *$ : $<0.01$, f: $p<0.002,{ }^{\$}$ : (AKG+PHA $100 \%$ vs. AKG) $p<0.02$,

: (AKG+PHA $100 \%$ vs. AKG+PHA $1 \%$ ) $p<0.02,{ }^{1}:$ (m) vs. (f) $p<0.05,{ }^{2}:$ (m) vs. (f) $p<0.04,{ }^{3}:$ (m) vs. (f) $p<0.03,{ }^{4}:$ (m) vs. (f) $p<0.009,,^{5}:$ (m) vs. (f) $\mathrm{p}<0.005$ 
Table 3: Proximal GI-tract morphology (crypt depth and tunica mucosa thickness) of adult Control rats, or rats treated with $\mathrm{AKG}, \mathrm{AKG}+\mathrm{PHA} 100 \%$ or $\mathrm{AKG}+\mathrm{PHA} 1 \%$ for 7 days. Values are means \pm SEM

\begin{tabular}{lll}
\hline Groups & Crypt depth $(\mu \mathrm{m})$ & $\begin{array}{l}\text { Thickness of tunica } \\
\text { mucosa }(\mu \mathrm{m})\end{array}$ \\
\hline Control & $170.8 \pm 17.6$ & $709.7 \pm 49.1$ \\
AKG & $194.5 \pm 17.7^{*}$ & $762.0 \pm 56.7^{*}$ \\
AKG+PHA $100 \% \$$ & $247.7 \pm 19.5^{* *}$ & $848.8 \pm 52.6^{* *}$ \\
AKG+PHA 1\% & $197.7 \pm 47.4^{* *}$ & $774.1 \pm 33.4^{* *}$ \\
\hline F-test (ANOVA) for both parameters: $\mathrm{p}<0.001, *: \mathrm{p}<0.05, * *:$ \\
p $<0.001$, \$: $(\mathrm{m})$ vs. (f) $\mathrm{p}<0.009$
\end{tabular}

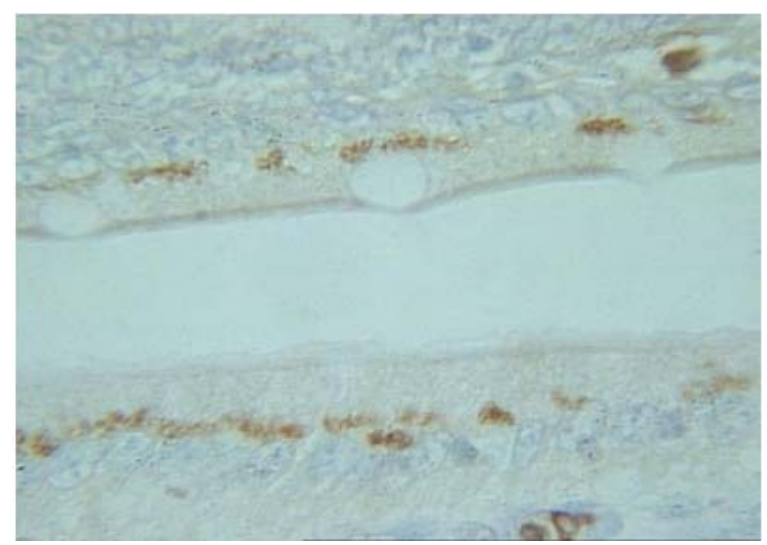

Fig. 2: Several positive IHC glutamate stains found in the enterocytes, located supra-nucleus, of AKG treated rats

The results of immunohistochemical examination of the proximal part of the small intestine showed a significant difference in the abundance of glutamatepositive enterocytes in the AKG treated rats, compared to that of Controls (Fig. 1 and 2). Cells staining positively for glutamate formed clusters and staining was localised to the supra-nucleus. Glutamate positive enterocytes were not abundant in the AKG+PHA $100 \%$ treated rats. Furthermore, there was a large difference in staining intensity between neighbouring cells and the glutamate-positive material was spread throughout the cells' cytoplasm (Fig. 3 ). In the AKG+PHA 1\% treated rats, glutamate positive staining was noted in the cytoplasm of enterocytes of only a very few villi and here the staining was found to be localised at the tip of each villus (Fig. 4).

Urinary and faecal $\mathbf{N}$ : Although a negative average daily gain was found for all four groups, only in the AKG and AKG+PHA 100\% groups was this associated with a negative apparent $\mathrm{N}$ balance. There was also a significant reduction in the amount of faeces excreted by the AKG group compared with the Control rats $(p<0.05)$. Furthermore there was a trend towards a

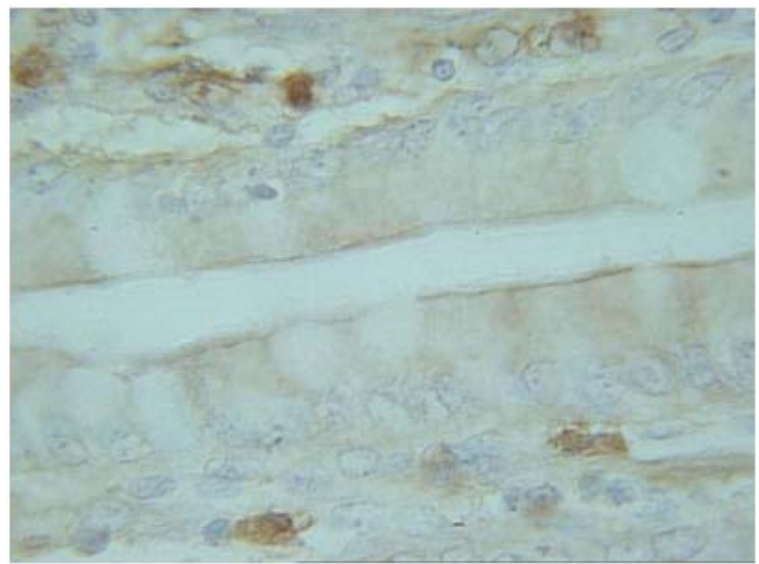

Fig. 3: The IHC stained material with positive glutamate staining was spread within the cells cytoplasm of AKG+PHA 100 treated rats

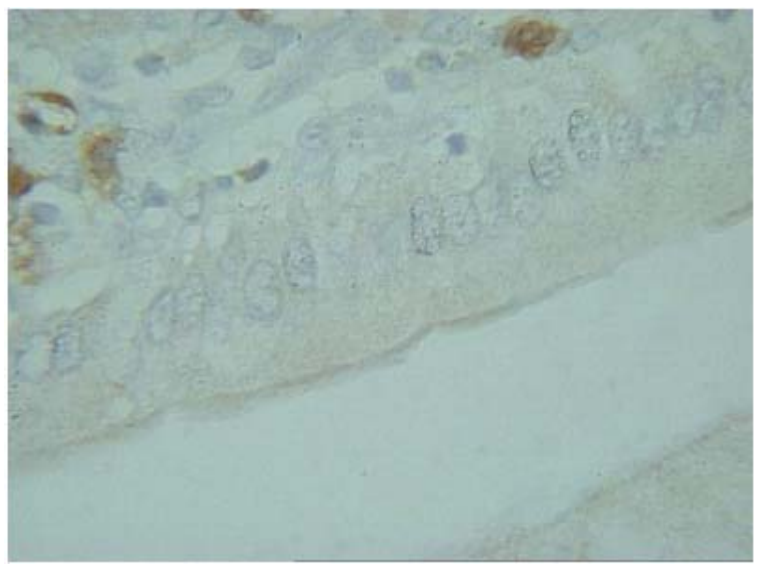

Fig. 4: Staining with IHC proved glutamate positive in the enterocytes cytoplasm in villi top, of $\mathrm{AKG}+\mathrm{PHA}$ treated rats

reduction in $\mathrm{N}$ excretion in urine for the $\mathrm{AKG}+\mathrm{PHA}$ $100 \%$ group, compared to that of the Controls (14.3\% lower), however, this was not found to be statistically significant (Table 4).

A calculation of the relative level of $\mathrm{N}$ in faeces to total $\mathrm{N}$ intake (Faecal N/intake $\mathrm{N} \%$ ) in the AKG+PHA $100 \%$ rats, shows what appears to be an increase in the $\mathrm{N}$ excreted in faeces compared with the Controls and treatment groups AKG and AKG+PHA 1\%. Finally, a similar pattern was found for the same group of rats when a calculation of the percentage of faecal $\mathrm{N}$ excreted in relation to the $\mathrm{N}$ excreted in faeces and urine $($ Faecal $\mathrm{N} /($ urine $\mathrm{N}+$ faecal $\mathrm{N}) \%$ ) was made (Table 4). 
Am. J. Pharm. \& Toxicol., 2 (4):170-177, 2007

Table 4: Nitrogen analyses of adult Control rats, or rats treated with AKG, AKG+PHA $100 \%$ or AKG+PHA $1 \%$ for $\mathrm{x}$ weeks. Values are means \pm SEM

\begin{tabular}{lllll}
\hline Days 0-7 & $\begin{array}{l}\text { Control } \\
(\mathrm{n}=5)\end{array}$ & $\begin{array}{l}\text { AKG } \\
(\mathrm{n}=6)\end{array}$ & $\begin{array}{l}\text { AKG+ PHA 100\% } \\
(\mathrm{n}=6)\end{array}$ & $\begin{array}{l}\text { AKG+PHA 1\% } \\
(\mathrm{n}=6)\end{array}$ \\
\hline Intake N $(\mathrm{g} \mathrm{N})^{\mathrm{b}}$ & $2.97 \pm 0.10^{1}$ & $3.05 \pm 0.27$ & $2.54 \pm 0.31$ & $3.07 \pm 0.21$ \\
Urine N (g N) & $2.24 \pm 0.24$ & $2.51 \pm 0.19$ & $1.92 \pm 0.24$ & $2.20 \pm 0.19$ \\
Faecal N (g N) & $0.71 \pm 0.05$ & $0.76 \pm 0.07$ & $0.74 \pm 0.09$ & $0.75 \pm 0.04$ \\
N for growth (g N) & $-0.33 \pm 0.19$ & $-0.53 \pm 0.20$ & $-0.86 \pm 0.28$ & $-0.56 \pm 0.16$ \\
Apparent N balance & 0.02 & -0.22 & -0.12 & 0.12 \\
Urine N/intake N\% & 75.4 & 82.2 & 75.5 & 71.6 \\
Faecal N/intake N\% & 23.9 & 24.9 & 29.1 & 24.4 \\
Faecal N/(urine N+faecal N)\% & 24.0 & 23.2 & 27.8 & 25.4 \\
\hline
\end{tabular}

HCL (pH 5.1) (HCL) and $\alpha$-ketoglutarate (AKG) (pH 5.1) combined with Phytohemagglutinin (AKG + PHA) at two different levels. ${ }^{a}:$ Average initial and final weights were $427.7 \mathrm{~g}$ and $405.1 \mathrm{~g}$, respectively; ${ }^{\mathrm{b}}$ : The calculated level of consumed nitrogen $=($ Total feed consumption*protein level in feed $(0.1967) *$ true protein dig. $(0.868)) / 6.25 ;^{\mathrm{c}}$ : The calculated level of nitrogen used for growth $=($ Total growth, $\mathrm{g} *$ the level of protein in flesh $(0.16)) / 6.2 ;{ }^{1}$ : (m) vs. (f) $\mathrm{p}<0.009$

Individuals aged 64 or more use on average 2-3 forms of medication daily. Moreover, drug-induced injury of the GI-tract, whilst increasingly more common, often goes un-recognized in individuals. Typically, one finds at the macroscopic level that drugs induce erosions and ulcers throughout the GI-tract, whilst, at the microscopic level, changes are mostly typified by erosion of tissue layers ${ }^{[18]}$.

Rat performance: In the present study, PHA treatment in elderly rats affected both performance and food intake in a negative way, findings that support work showing that ingestion of PHA (from red kidney beans) results in a reduction in body weight and at high doses may even damage the gut mucosa ${ }^{[18]}$. Moreover, the effect of PHA on the intestinal wall is not a homogenous one. Whether PHA induces a reversible dose-dependent hyperplastic growth of the intestinal wall ${ }^{[4]}$ or damage is entirely dose dependent. Thus it is quite possible in one study to observe a strong antinutritional effect and in another study an improvement in performance ${ }^{[19]}$.

In accordance with previous experiments, albeit on young animals ${ }^{[17]}$, the present study found that PHA treatment had no adverse effect on GI-tract weight with respect to stomach, small intestine, large intestine, or caecum. A lighter total GI-tract weight was measured for both the AKG and AKG+PHA 1\% groups, compared with that of the Control rats. Thus, it seems reasonable to conclude from the present data that PHA at a high dose serves to protect the GI-tract from an AKG related decrease in weight.

Gastro-intestinal tract morphology: Plant lectins are known to bind avidly to the mucosal surface of the GItract, inducing dose-, time-dependent and fully reversible hyperplastic and hypertrophic growth of the small intestine ${ }^{4}$. Earlier studies suggest that an increase in the growth of the small intestine following PHA treatment is achieved through an elevated rate of cellular production ${ }^{4-7}$. It is very likely, that PHA acts as an extraneous growth factor in the gut, binding to cell surface receptors of the brush border membrane in a similar fashion to some other hormones and peptide growth factors. Indeed, it has been shown that PHA induces extensive proliferation and changes in the metabolism of epithelial cells via activation of secondary messenger pathways, such changes being the result of activated by PHA of brush border epithelial receptors ${ }^{[4]}$. In the present study, crypt depth and the thickness of the tunica mucosa in the proximal part of the small intestine was significantly increased in the PHA treated rats comparing to that of the Controls. Moreover, the effect was far more pronounced in those animals that were administered a high dose of PHA (AKG+PHA 100\%). These data, not only support, but also augment previous findings in which authors have attributed an increase in the weight of the small intestine to an increase in the rate of production of cells, as indicated by a greater crypt depth ${ }^{[4,7,17,20,21]}$. It is concluded therefore that PHA at a high dose and in combination with AKG may serve to protect against drug-induced erosion of GI-tract tissue layers, or at the very least help to quickly repair such injuries.

Effect of PHA and AKG on the elderly gut: AKG is absorbed far more efficiently from the upper small intestine than from more distal regions. Furthermore, orally administered AKG is rapidly removed from the systemic circulation with a half-life of under $5 \mathrm{~min}^{[22]}$. Only $40 \%$ of AKG is taken up and metabolized to $\mathrm{CO}_{2}$ in the intestinal mucosa in the first pass ${ }^{[10]}$, the remainder generally following common metabolic pathways via glutamate to other amino acids (e.g. proline). In the intestine, glutamate is channelled towards proline (and ornithine) synthesis [via glutamic- 
$\gamma$-semialdehyde] because of AKG derived saturation of the oxidative needs of the enterocytes ${ }^{[23]}$. Thus the present study not only supports tracer studies ${ }^{[23,24]}$, it also provides additional evidence (IHC analysis), that AKG treatment has a beneficial impact on the level of glutamate metabolised by enterocytes in the proximal small intestine. Thus, one might speculate that the increased level of glutamate found in AKG treated rats, may be seen as indicative of an increased part of the ingested feed nitrogen bound within the gastrointestinal tract made available for further metabolic processing to, for example, glutamine and proline formation following such treatment. Such a change might also be expected to affect the $\mathrm{N}$ balance of an individual. However, whilst the present data concerning $\mathrm{N}$ balance and the precise urinary and faecal losses are far from conclusive, there does appear to be a trend indicative of an altered proportion of $\mathrm{N}$ excreted in urine cf. that in the faeces, in support of this line of reasoning, such that faecal $\mathrm{N}$ excretion appears to be favoured in elderly rats administered a high dose of PHA in combination with AKG. Interestingly, administration of AKG alone does not have such an effect on $\mathrm{N}$ excretion.

When comparing the present data with those of previous experiments performed on young growing rats $^{[17]}$, the main impression is that elderly rats appear to have a reduced ability to utilise nitrogen for growth or other metabolic processes, which is in agreement with the findings of animal and clinical reports ${ }^{[1,2]}$. Indeed, Lee $e t a l .^{[1]}$ have shown a down-regulation of gene expression with ageing in the rat duodenum of such

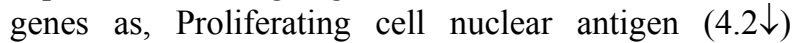
regulating cell proliferation, $17 \mathrm{kDa}$ Ubiquitin-

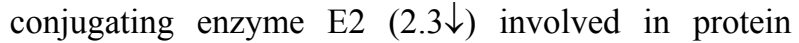
turnover, Cytochrome c oxidase (subunits Va and VIIa) $(2.2 \downarrow)$ regulating oxidative phosphorylation and

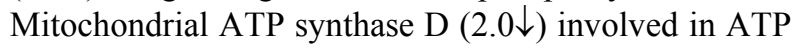
production.

Over half a century ago, Mudge $(1951)^{[25]}$, showed in a study of potassium accumulation by rabbit kidney slices, that oxygen consumption $\mathrm{h}^{-1}$ per mg wet weight of tissue increased by $209 \%$ cf. control levels upon addition of AKG. We therefore suggest that the data of Mudge $^{[25]}$, which provides clear evidence of a significant increase in cellular metabolism after exposure to $\mathrm{AKG}$, combined with the results of Bardocz $^{[4]}$ and those of Linderoth et al. ${ }^{[7]}$ showing PHA stimulated growth of the small intestine to be achieved through an elevated rate of cellular production, lend considerable weight to explaining the beneficial role of combined AKG and PHA administration on enhanced crypt depth and tunica mucosa growth observed in our elderly rats. Indeed, one might speculate that this AKG+PHA synergy is achieved through either inhibition of the senescent down-regulation of the proliferative and metabolic genes identified by ${ }^{[1]}$, or a synergetic stimulation of cellular growth and provision of metabolic reserves necessary to support protein synthesis.

\section{CONCLUSION}

The present study indicates that in older rats, oral PHA in combination with AKG, induces an increase in crypt depth and the thickness of the tunica mucosa of the small intestine, changes that occur independently of stimulation of GI-tract growth. The apparent trend indicative of an altered proportion of $\mathrm{N}$ excreted via urine and faeces, apparently favouring faecal $\mathrm{N}$ excretion with AKG+PHA $100 \%$ administration warrants further investigation. It is concluded that findings from the present study reveal a new perspective in terms of the treatment of injured intestinal mucosa in the elderly, although it is proposed that further studies are needed in order to elucidate the precise action and role of AKG and PHA.

\section{REFERENCES}

1. Lee, H.M., G.H. Greeley and E.W. Englander, 2001. Age-associated changes in gene expression patterns in the duodenum and colon of rats. Mech. Ageing Dev., 122: 355-371.

2. Woudstra, T. and A.B. Thomson, 2002. Nutrient absorption and intestinal adaptation with aging. Best Pract. Res. Clin. Gastroenterol., 16: 1-15.

3. Pusztai, A., S.W. Ewen, G. Grant, W.J. Peumans, E.J. van Damme, L. Rubio and S. Bardocz, 1990. Relationship between survival and binding of plant lectins during small intestinal passage and their effectiveness as growth factors. Digestion, 46: 308-316.

4. Bardocz, S., 1996. Effect of phytohaemagglutinin on intestinal cell proliferation. Role of polyamines. Arch. Lationam. Nutr., 44: 16-20.

5. Linderoth, A., O. Prykhod'ko, B. Ahren, F. Fak, S.G. Pierzynowski and B.R. Westrom, 2006. Binding and the effect of the red kidney bean lectin, phytohaemagglutinin, in the gastrointestinal tract of suckling rats. Br. J. Nutr., 95: 105-115.

6. Linderoth, A., O. Prykhod'ko, S.G. Pierzynowski and B.R. Westrom, 2006. Enterally but not parenteralny administered Phaseolus vulgaris lectin induces growth and precocius maturation of the gut in suckling rats. Biol. Neonate., 89: 60-68. 
7. Linderoth, A., M. Biernat, O. Prykhodko, I. Kornilovska, A. Pusztai, S.G. Pierzynowski and B. Westrom, 2005. Induced growth and maturation of the gastrointestinal tract after Phaseolus vulgaris lectin exposure in suckling rats. J. Pediatr. Gastroenterol. Nutr., 41: 195-203.

8. Wernerman, J. and F. Hammarqvist, 1999. Modulation of endogenous glutathione availability. Curr. Opin. Clin. Nutr. Metab. Care, 2: 487-492.

9. Le Bricon, T., C. Coudray-Lucas, N. Lioret, S.K. Lim, F. Plassart, L. Schlegel, J.P. De Bandt, R. Saizy, J. Giboudeau and L. Cynober, 1997. Ornithine alphaketoglutarate metabolism after enteral administration in burn patients: Bolus compared with continous infusion. Am. J. Clin. Nutr., 65: 512-518.

10. Junghans, P., M. Derno, S.G. Pierzynowski, U. Hennig and W.B. Souffrant, 2003. Utilization of a-ketoglutarate $(\mathrm{AKG})$ in young growing pigs after intra-venous and intra-duodenal administration. The EAAP-Symposium (European Association for Animal Production) on Energy and Protein Metabolism and Nutrition, Rostock-Warnemunde, Germany, September 2003, pp: 521-523.

11. Lambert, B.D., R. Filip, B. Stoll, P. Junghans, M. Derno, U. Hennig, W.B. Souffrant, S.G. Pierzynowski and D.G. Burrin, 2006. Firstpass metabolism limits the intestinal absorption of enteral a-ketoglutarate in young pigs. J. Nutr., 136: 2779-2784.

12. Wu, G., 1995. Urea synthesis in enterocytes of developing pigs. Biochem. J., 312: 717-723.

13. Rhoads, J.M., R.A. Argenzio and W. Chen, 1997. L-glutamine stimulates intestinal cell proliferation and activates mitogen-activated protein kinases. Am. J. Physiol., 272: 943-953.

14. Wiren, M., J. Permert and J. Larsson, 2002. Alphaketoglutarate-supplemented enteral nutrition: Effects on postoperative nitrogen balance and muscle catabolism. Nutr., 18: 725-728.

15. Welborn, J.R., S . Shpun, W.H. Dantzler and S.H. Wright, 1998. Effect of alpha-ketoglutarate on organic anion transport in single rabbit renal proximal tubules. Am. J. Physiol., 274: 165-174.

16. Filip, R.S., S.G. Pierzynowski, B. Lindegard, J. Wernerman, A. Haratym-Maj and M. Podgurniak, 2007. Alpha-ketoglutarate decreases serum levels of c-terminal cross-linking telopeptide of type i collagen (CTX) and preserves bone mass in postmenopausal women with osteopenia: Six-month study. Int. J. Vit. Nutr. Res., 77: 89-97.
17. Filip, R., A. Harrison, M. Bieńko, R.P. Radzki and S.G. Pierzynowski, 2007. Dietary supplementation with phytohemagglutinin in combination with $\alpha$ ketoglutarate limits the excretion of protein via the urinary tract in rats, in press.

18. Parfitt, J.R. and D.K. Driman, 2007. Pathological effects of drugs on the gastrointestinal tract: A Rev. Hum. Pathol., 38: 527-536.

19. Thomsson, A., D. Rantzer, B.R. Westrom, S.G. Pierzynowski and J. Svendsen, 2007. Effects of crude red kidney bean lectin (phytohemagglutinin) exposure on performance, health, feeding behaviour and gut maturation of pigs at weaning. J. Anim. Sci., 85: 477-485.

20. Radberg, K., M. Biernat, A. Linderoth, R. Zabielski, S.G. Pierzynowski and B.R. Westrom, 2001. Exposure to crude red kidney bean lectin induces maturation of the gut in suckling pigs. J. Anim. Sci., 79: 2669-2678.

21. Banwell, J.G., R. Howard, I. Kabir, T.E. Arian, R.H. Diamond and C. Abramowsky, 1993. Small intenstinal growth caused by feeding red kidney bean phytohemagglutinin lectin to rats. Gastroenterology, 104: 1669-1677.

22. Dabek, M., D. Kruszewska, R. Filip, A. Hotowy, Ł. Pierzynowski, A. Wojtasz-Pająk, S. Szymczyk, J.L. Valverde-Piedra, E. Werpachowska and S.G. Pierzynowski, 2005. $\alpha$-ketoglutarate (AKG) absorption from pig intestine and plasma pharmacokinetics. J. Anim. Physiol. Anim. Nutr., 89: 419-426.

23. Kristensen, N.B., H. Jungvid, J.A. Fernandez and S.G. Pierzynowski, 2002. Absorption and metabolism of $\alpha$-ketoglutarate in growing pigs. J. Anim. Physiol. Anim. Nutr., 86: 239-245.

24. Lambert, B.D., R. Filip, B. Stoll, H. Niinikoski, A. Sunehag, P. Junghans, M. Derno, U. Hennig, W.B. Souffrant, S.G. Pierzynowski and D.G. Burrin, 2006. First-pass metabolism limits the intestitinal absorption of enterally infused $\alpha$ ketoglutarate in young pigs. J. Nutr., 136: 2779-2784.

25. Mudge, G.H., 1951. Studies on potassium accumulation by rabbit kidney slices: Effect of metabolic activity. Am. J. Physiol., 165: 113-127. 